\title{
Viabilidade técnica de fontes alternativas de adubação para o alho (Allium sativum L.) vernalizado no planalto Catarinense
}

Technical viability of alternative fertilization sources for vernalized garlic (Allium sativum L.) on Santa Catarina's plateau

\section{Jonatas Thiago Piva ${ }^{1 *}$, Marcos Renan Besen ${ }^{3}$, Ricardo Henrique Ribeiro ${ }^{1}$, Alessandra Carvalho Maciel Bastos $^{1}$, Sabrina Carvalho Ronsani ${ }^{1}$ e Claudia Aparecida Guginski Piva ${ }^{2}$}

Recebido em 03/03/2016 / Aceito em 01/03/2017

\section{RESUMO}

O alho é exigente em termos de fertilidade do solo, sendo considerado responsivo a aplicação de nutrientes. Desta forma, o objetivo foi avaliar o efeito de fontes alternativas de fertilizantes sobre a viabilidade técnica e econômica do alho vernalizado, cultivar Roxo Caxiense, na região do planalto Catarinense. $\mathrm{O}$ experimento foi conduzido no delineamento experimental de blocos ao acaso com quatro tratamentos (controle; adubo mineral; cama de aviário; cinza vegetal de caldeira) e quatro repetições. As doses utilizadas foram 0, 1250, 10000 e $15000 \mathrm{~kg}$ ha $^{-1}$ para o tratamento controle, adubação mineral, cinza e cama de aviário, respectivamente. A cultivar utilizada foi a Roxo Caxiense, sendo selecionado para o plantio bulbos $\mathrm{n}^{\circ}$ 5. Avaliou-se diâmetro, massa e produtividade de bulbos, bem como aspectos econômicos relacionados às fontes de adubação. Para o diâmetro de bulbo as fontes diferiram apenas do tratamento controle. Assim, a classificação do alho, nos tratamentos com adubação, ficou em classe 5, enquanto no controle foi classe 4. Para massa de bulbos e produtividade a cama de aviário obteve média superior ao uso de cinza e ao tratamento controle, mas não diferiu da adubação mineral. Contudo, observou-se incremento em produtividade ao utilizar cama de aviário em relação à adubação mineral, e consequentemente maior lucro total por área. A cinza resultou em baixo investimento, porém pela produtividade inferior, obteve menor lucro por área comparado a adubação mineral e cama de aviário. Nas condições de clima e solo do presente estudo a adubação orgânica com cama de aviário mostrou ser viável, gerando incremento de 5,6 e $14,5 \%$ em produtividade de bulbos em relação ao uso de adubo mineral e cinza vegetal, respectivamente. $\mathrm{O}$ uso de cama de aviário apresentou lucro por hectare de $\mathrm{R} \$ 2.178,2$ a mais que a adubação mineral.

PALAVRAS-CHAVES: adubação orgânica, produtividade, cinza de caldeira e cama de aviário.

\section{ABSTRACT}

The garlic demand in soil fertility terms and is considered responsive to nutrients application. Thus, the objective was to evaluate the alternative source effects of fertilizers on the technical and economic viability of vernalized garlic, Roxo Caxiense cultivar, in the Santa Catarina plateau region. The experiment was conducted in randomized blocks experimental design using four treatments (control treatment, mineral fertilizer, poultry litter, and vegetable ash from boiler) and four replications. The used doses were $0,1250,10000$ and $15000 \mathrm{~kg} \mathrm{ha}^{-1}$ for the control treatment, mineral fertilization, vegetable ash and poultry litter, respectively. The cultivar used was Roxo Caxiense, with $n^{\circ} 5$ bulbs selected for planting. The diameter, mass and bulbs productivity were evaluated, as well as economic aspects related to the sources of fertilization. For the bulb diameter, the sources differed only from the control treatment. Thus, the garlic classification in treatments with fertilization was class 5 , while in the control it was class 4 . For bulb mass and productivity, the poultry litter demonstrated a superior average to the ash use and the control treatment, but did not differ from the

${ }^{1}$ Universidade Federal de Santa Catarina, Curitibanos, SC, Brasil.

${ }^{2}$ Universidade do Oeste de Santa Catarina, Campos Novos, SC, Brasil.

${ }^{3}$ Universidade Estadual de Maringá, Maringá, PR, Brasil.

${ }^{4}$ Universidade Federal do Paraná, Curitiba, PR, Brasil.

*Autor para correspondência <jonatas.piva@ufsc.br> 
mineral fertilization. However, productivity increase was observed when using poultry litter in relation to mineral fertilization, and consequently higher total profit per area. The ash resulted in low investment, but due to lower productivity, it obtained lower profit per area compared to mineral fertilization and poultry litter. In the soil and climate conditions of the present study, organic fertilization with poultry litter proved to be viable, generating an increase of 5.6 and $14.5 \%$ in bulb productivity in relation to the use of mineral fertilizer and vegetable ash, respectively. The use of poultry litter presented the profit per hectare of $\mathrm{R} \$$ 2,178.2 more than mineral fertilization.

KEYWORDS: organic fertilization, productivity, ash from boiler and poultry litter.

\section{INTRODUÇÃO}

O alho apresenta relevada importância no planalto Catarinense, tanto no aspecto econômico como social. O incentivo a produção de alho nessa região do estado foi desencadeado após o surgimento da cultivar de alho nobre Chonan, a qual teve importância imprescindível na expansão da cultura nos estados do Sul do país (BIASI 1991).

Em 2014 foram produzidos 101,6 mil toneladas de alho no Brasil, sendo o estado de Santa Catarina o terceiro maior produtor a nível nacional, produzindo 19 mil toneladas somente em 2013, sendo o município de Curitibanos, SC responsável por 9 mil toneladas do total de alho produzido (EPAGRI/CEPA 2014). Contudo o alho brasileiro atende cerca de $32 \%$ da demanda nacional, sendo necessário a importação dessa olerícola, fato que faz com que o Brasil se torne um dos maiores importadores de alho a nível mundial (EPAGRI/CEPA 2014).

O alho é uma cultura exigente em termos de fertilidade do solo, sendo uma cultura considerada responsiva a aplicação de nutrientes no solo. Contudo as exigências relacionadas à absorção e acúmulo dos nutrientes no solo estão sujeitas a variações, principalmente, em função da espécie utilizada, do manejo empregado e das condições específicas ao local de cultivo (BIASI 2006). Para tal, o uso de fontes alternativas de fertilizantes deve ser avaliado, visando reduzir o custo e buscando incrementar a lucratividade do agricultor.

A indústria madeireira no planalto Catarinense gera grandes quantidades de resíduos na forma de cinza, oriundo do processo de queima do material vegetal no processo industrial. Este resíduo vem sendo empregado como adubo na agricultura, pois, apresenta em sua composição alguns macronutrientes, como, fósforo $(\mathrm{P})$, potássio $(\mathrm{K})$, cálcio $(\mathrm{Ca}) \mathrm{e}$ magnésio $(\mathrm{Mg})$ além de outros nutrientes capazes de influenciar no desenvolvimento e produção das plantas cultivadas (BONFIM-SILVA et al. 2011). Entretanto, são necessárias informações mais concisas sobre as consequências da aplicação desses resíduos nas propriedades químicas, físicas e biológicas do solo, concomitante com seu efeito na produtividade das culturas.

Em estudo realizado em solo Latossolo Vermelho Amarelo, SOUZA et al. (2013) verificaram aumento do $\mathrm{pH}$ e da concentração de $\mathrm{Ca}, \mathrm{Mg}, \mathrm{P}$ e K de forma linear com o uso de doses crescentes de cinzas de caldeira, atuando também na correção da acidez do solo. Nesse sentido, SILVA et al. (2013), por sua vez constataram baixa eficiência da cinza em neutralizar a acidez do solo, apresentando poder de neutralização (PN) de apenas 7\%. O uso de cinza vegetal na adubação de hortícolas, como o da rúcula em Latossolo Vermelho proporcionou aumento na produtividade e uma melhoria em relação ao uso da água pelas plantas (BONFIM-SILVA et al. 2011).

Outra alternativa visando atender a demanda nutricional da cultura doalho eempregada, comumente, por alguns agricultores trata-se da adubação orgânica mediante uso de dejetos de animais, à exemplo da cama de aviário. Seu uso é justificado pelo potencial fertilizante e condicionador do solo, bem como da necessidade de realocar o material proveniente das granjas de aves, visto que o estado de Santa Catarina é um dos principais produtores nacionais de carne de frango (LOURENÇO et al. 2013). Em estudo realizado por ZHANG et al. (2002), avaliando 240 amostras de cama de aviário oriundas de frangos de corte com umidade de $23 \%$ foram observados valores médios de 2,7 $\mathrm{g} \mathrm{kg}^{-1}$ de $\mathrm{P}, 2,3 \mathrm{~g} \mathrm{~kg}^{-1}$ de $\mathrm{K}$ e 2,3 $\mathrm{g} \mathrm{kg}^{-1} \mathrm{de}$ N. Porém, devido à grande variação nos valores dos atributos químicos de fertilizantes orgânicos, devido à fatores como tempo de compostagem e origem do material (WU \& MA 2002), MORAL et al. (2005) concluíram que não é correto fazer generalizações quanto aos teores dos elementos nas frações orgânicas predominantes e quanto à velocidade de liberação dos mesmos. Sendo assim, afirmam a necessidade de se caracterizar esses materiais antes de sua adição ao solo. 
Além das melhorias no aspecto químico, físico e biológico que a adubação orgânica pode proporcionar ao solo (BAYER \& MIELNICZUK 1999), a margem de lucro a partir de fontes orgânicas e alternativas pode ser otimizada, pois estas são de baixo custo para o produtor. Com base nesses pressupostos e da necessidade de otimizar informações sobre essa temática, esse trabalho foi conduzido com a hipótese de que adubos orgânicos, de origem vegetal ou animal, podem suprir a demanda nutricional da cultura do alho, equivalendo-se a fertilização mineral, associado ao menor custo de produção.

O objetivo do trabalho foi avaliar o efeito de fontes alternativas de fertilizantes sobre o desempenho do alho vernalizado, cultivar Roxo Caxiense, analisando a viabilidade econômica na região do planalto Catarinense.

\section{MATERIAL E MÉTODOS}

$\mathrm{O}$ experimento foi conduzido à campo, entre os meses de julho à dezembro em Curitibanos, SC, nas coordenadas geográficas de $27^{\circ} 16^{\prime} 44^{\prime \prime}$ de latitude Sul, e 50 $34^{\prime} 57^{\prime}$ ' de longitude, com altitude de 987 metros. Anteriormente à implantação do experimento a área em estudo foi cultivada com soja, sendo que na propriedade adota-se a sucessão sojaalho há cinco anos. O solo é classificado como um Cambissolo Háplico de textura argilosa (EMBRAPA 2013). A caracterização química do solo, realizada na profundidade de $0-0,2 \mathrm{~m}$, antes da implantação do experimento apresentaram os seguintes valores: matéria orgânica (MO) $60 \mathrm{~g} \mathrm{~kg}^{-1}, \mathrm{pH} \mathrm{em} \mathrm{CaCl}_{2} 5,1$, saturação de bases (V\%) 68,7\%, fósforo (P) 11,2 $\mathrm{mg} \mathrm{dm}{ }^{-3}$, potássio, alumínio, cálcio e magnésio $(\mathrm{K}$, $\mathrm{Al}^{+3}, \mathrm{Ca}$ e $\mathrm{Mg}$ ), apresentou os seguintes valores 0,2 , 0,0, 6,1 e 2,9 $\mathrm{cmol}_{\mathrm{c}} \mathrm{dm}^{-3}$, respectivamente. A MO foi extraída pelo método de Walkley Black, $\mathrm{P}$ e K por Mehlich $1, \mathrm{Al}^{+3}$, Ca e $\mathrm{Mg}$, por $\mathrm{KCl} 1 \mathrm{~mol} \mathrm{~L}^{-1}$ conforme metodologia descrita por SANTOS et al. (2009).

$\mathrm{O}$ clima da região é classificado como $\mathrm{Cfb}$ temperado de acordo com Köppen. A precipitação anual situa-se entre 1500 a $1700 \mathrm{~mm}$, com temperatura média entre $16{ }^{\circ} \mathrm{C}$ e $17{ }^{\circ} \mathrm{C}$ (PANDOLFO et al. 2002). Segundo as informações obtidas da estação meteorológica da UFSC, campus de Curitibanos, a temperatura média durante o experimento foi de $15,3{ }^{\circ} \mathrm{C}$, e a precipitação acumulada de $757 \mathrm{~mm}$, sendo as chuvas bem distribuídas durante os meses de avaliação, e no caso de restrição hídrica, foi realizado irrigação por aspersão.

O delineamento experimental utilizado foi o de blocos completos ao acaso composto por quatro tratamentos e quatro repetições. Foram avaliadas diferentes fontes de adubação, compondo os seguintes tratamentos: T1- tratamento controle; T2 - adubação mineral com NPK; T3 - adubação orgânica com uso de cama de aviário; T4 - adubação com cinza vegetal. Cada unidade experimental foi composta de uma área de $16 \mathrm{~m}^{2}(4 \mathrm{x} 4 \mathrm{~m})$, com área útil de $4 \mathrm{~m}^{2}$. No preparo do solo, efetuou - se a calagem a fim de elevar o $\mathrm{pH}$ a 6,0 conforme manual de adubação e calagem para os estados do Rio Grande do Sul e Santa Catarina (CQFS-RS/SC 2004). A incorporação do calcário foi a $0,20 \mathrm{~m}$ de profundidade, após a subsolagem, com uso de enxada rotativa de 1,6 $\mathrm{m}$ de largura.

As recomendações das doses de cada adubo foram baseadas considerando a quantidade de fósforo do solo, a uma expectativa de rendimento de $12000 \mathrm{~kg} \mathrm{ha}^{-1}$ de alho considerando o teor médio de P de cada fonte, correspondendo a 1250, 10000 e $15000 \mathrm{~kg} \mathrm{ha}^{-1}$ de adubação mineral, cinza e cama de aviário, respectivamente. Os teores de nutrientes dos fertilizantes utilizados no experimento estão descritos na Tabela 1.

A cama de aviário utilizada foi oriunda da criação de frangos para corte, composta inicialmente de maravalha e serragem. $\mathrm{Na}$ cama passaram 8 lotes de frangos, com duração de 35 dias, mais 10 dias de intervalo entre os lotes, totalizando 360 dias. Após o término do ciclo, a cama foi retirada do aviário, permanecendo em fermentação 30 dias até sua utilização. A cinza utilizada foi proveniente da queima de madeira de Pinus taeda para produção de energia na empresa BERNECK, no município de Curitibanos, SC. A adubação mineral foi realizada por meio do adubo formulado 03-20-16, com Ca e S (9 e $5 \%$ ). Os fertilizantes (orgânicos e minerais) foram aplicados em dose única no dia do plantio, em área total e incorporados a $20 \mathrm{~cm}$ com auxílio de enxada rotativa. Não houve reposição de adubação em cobertura.

A cultivar utilizada foi a Roxo Caxiense, sendo selecionado para o plantio bulbos $\mathrm{n}^{\circ} 5$ (de acordo com a classificação da Portaria $\mathrm{n}^{\circ} 242$, de 17 de setembro de 1992, do Ministério da Agricultura e Reforma Agrária). Os bulbos sementes foram submetidos ao processo de vernalização, por um período de 28 dias em câmara, com temperatura média de $4{ }^{\circ} \mathrm{C}$. 
Tabela 1. Composição química total dos adubos avaliados, quantidade de nutrientes em função da dose aplicada de cada fonte e necessidade da cultura a partir da análise de solo e expectativa de produtividade. Curitibanos, SC. 2013.

Table 1. Total chemical composition of the evaluated fertilizers, amount of nutrients as a function of the applied dose of each source and crop need from the soil analysis and productivity expectation. Curitibanos, SC. 2013.

\begin{tabular}{lccccccc}
\hline \multicolumn{1}{c}{ Composição química ${ }^{1}\left(\mathrm{~g} \mathrm{~kg}^{-1}\right)$} & $\mathrm{Ca}$ & $\mathrm{Mg}$ & $\mathrm{S}$ & $\mathrm{CO}$ \\
\hline Fontes & $\mathrm{N}$ & $\mathrm{P}$ & $\mathrm{K}$ & $\mathrm{Ca}$ & \\
\hline Cama de aviário $^{4}$ & 27,1 & 16,8 & 9,0 & 23,4 & 7,4 & - & 335,6 \\
Cinza & 1,6 & 25,9 & 30,3 & 25,3 & 7,3 & 2,9 & 15,1 \\
Adubo mineral (NPK) & 30,0 & 200,0 & 160,0 & 90,0 & - & 50,0 & - \\
\hline \multicolumn{7}{c}{ Quantidade de nutrientes em função da dose aplicada ${ }^{2}\left(\mathrm{~kg} \mathrm{ha}^{-1}\right)$} \\
Cinza & 406,5 & 252,0 & 135,0 & 351,0 & 111,0 & - & \\
Adubo mineral (NPK) & 16,0 & 259,0 & 303,0 & 253,0 & 73,0 & 29,0 & \\
\hline
\end{tabular}

Exigência pela cultura ${ }^{3}\left(\mathrm{~kg} \mathrm{ha}^{-1}\right)$

$\leq 250,0 \quad 300,0 \quad 240,0$

${ }^{1} \mathrm{~N}$ = Nitrogênio; $\mathrm{P}$ = Fósforo; $\mathrm{K}$ = Potássio; $\mathrm{Ca}=$ Cálcio; $\mathrm{Mg}$ = Magnésio; $\mathrm{S}$ = Enxofre; $\mathrm{CO}$ = Carbono Orgânico.

${ }^{2}$ Quantidade calculada a partir do teor do nutriente por kg de fertilizante e pela dose aplicada.

${ }^{3}$ Exigência da cultura a partir da interpretação da análise de solo e expectativa de rendimento (CQFS-RS/SC 2004).

${ }^{4}$ Análise do resíduo orgânico conforme metodologia de TEDESCO et al. (1995).

Anteriormente ao plantio, os bulbilhos foram submetidos ao tratamento com a aplicação do ingrediente ativo Procimidona, o qual se trata de um fungicida indicado para o controle da podridão branca (Sclerotium cepivorum). O plantio foi realizado manualmente no dia 30 de julho de 2013, seguindo as recomendações de zoneamento agrícola para a região. Foram dispostas cinco linhas simples em cada unidade experimental com espaçamento de $0,26 \mathrm{~m}$ entrelinhas e espaçamento de $0,10 \mathrm{~m}$ entre bulbilhos na linha.

Durante o cultivo da cultura os tratos culturais, tais como, aplicações de fungicidas, herbicidas e inseticidas seguiram as recomendações técnicas para a cultura. Dessa forma, o controle das plantas daninhas foi efetuado com aplicação de herbicida seletivo de pós emergência princípio ativo octanoato de ioxinila, do grupo químico benzonitrila, quando as invasoras se apresentavam com 2 a 4 folhas definitivas. Posteriormente, realizou-se em duas ocasiões o controle de daninhas de forma manual em todas as parcelas.

A colheita foi realizada em 07 de dezembro de 2013. Foram colhidos dois metros lineares das duas linhas centrais, na área útil de cada unidade experimental, desprezando-se as bordaduras, totalizando 80 plantas. As plantas ficaram expostas ao sol por dois dias, período denominado como pré-cura e então armazenadas em um galpão por aproximadamente 40 dias correspondendo ao período de cura. Após o período de cura realizou-se a prática de toalete, que corresponde à retirada do caule e corte das raízes. Em seguida os bulbos das 15 plantas colhidas de maneira aleatória, foram pesados visando à determinação da massa média dos bulbos $(\mathrm{g}) \mathrm{e}$ medindo para obter o diâmetro médio dos bulbos (mm), com auxílio de um paquímetro digital.

A produtividade foi determinada a partir do conhecimento do peso médio dos bulbos obtidos na área útil de cada tratamento, extrapolando-os para $\mathrm{kg} \mathrm{ha}^{-1}$. Na análise da viabilidade econômica foram considerados os seguintes valores para os produtos avaliados, comercializados na região de Curitibanos no ano de 2013: R\$ 78,00 a saca de $60 \mathrm{Kg}$ do adubo mineral-NPK turbo 453; a cinza é um resíduo distribuído de forma gratuita por uma empresa do segmento madeireiro da região, tendo custos apenas com o frete ( $R \$ 10,0$ por tonelada) e $R \$ 150,00$ a tonelada de cama de aviário.

Os dados obtidos foram analisados quanto a normalidade dos erros e homocedasticidade das variâncias, por meio do teste Shapiro-Wilk e Bartlett, respectivamente. Não houve necessidade de transformação de dados, pois os pressupostos básicos foram atendidos, sendo assim os dados foram submetidos à análise de variância pelo teste F segundo o delineamento de blocos ao acaso. Quando houve 
diferença o efeito dos tratamentos foi comparado pelo teste de Tukey $(\mathrm{p}<0,05)$.

\section{RESULTADOS E DISCUSSÃO}

$\mathrm{O}$ diâmetro médio dos bulbos (DMB) foi influenciado pelas fontes avaliadas. Com o uso da cama de aviário e do adubo mineral, obtiveram-se os diâmetros de 45,3 e 46,5 mm, respectivamente, sendo superiores ao tratamento controle $(41,5 \mathrm{~mm})$ e semelhante ao tratamento com cinza $(43,8 \mathrm{~mm})$ (Tabela 2). A fertilização com cinza correspondeu ao diâmetro médio de bulbo de $43,8 \mathrm{~mm}$, não diferindo dos demais tratamentos, evidenciando que no presente estudo a adubação mineral não se sobressaiu em relação à adubação orgânica para essa variável (Tabela 2).

O efeito positivo do uso de cinza em olerícolas foi reportado por DAROLT et al. (1993), os quais avaliaram o efeito de doses sobre o desenvolvimento da alface e observaram maior diâmetro médio de cabeça quando realizada a aplicação de $10000 \mathrm{~kg} \mathrm{ha}^{-1}$ de cinza $\left(150,710,2320\right.$ e $2,1 \mathrm{~kg} \mathrm{ha}^{-1}$, de P, K, Ca, e Mg, respectivamente), resultado esse que correspondeu a um aumento de $34 \%$, quando comparado aos valores obtidos pelo tratamento controle.

De acordo com os resultados obtidos no presente estudo referente ao diâmetro médio dos bulbos (Tabela 2) do tratamento controle, esses se enquadram na classificação comercial 4 que varia de 37 a $42 \mathrm{~mm}$ de acordo com a Portaria n. 242 de 17/09/1992 do MAPA. Por sua vez, os demais tratamentos, que receberam alguma forma de adubação oriunda das diferentes fontes, se enquadram em uma categoria acima, correspondente a classe 5 (42 à $47 \mathrm{~mm}$ ) (MAPA 1992), preferível ao mercado consumidor e de maior valor agregado.

O preço médio pago em janeiro de 2014 (período que corresponde a pós-cura do alho colhido no presente estudo) em Santa Catarina, pela caixa de alho nobre de $10 \mathrm{~kg}$ foi de $\mathrm{R} \$ 40,00$, para as classes $4 \mathrm{e}$ 5. Contudo, melhores categorias podem ser atingidas com o cultivo da variedade Roxo Caxiense, a mesma utilizada nesse trabalho. Em estudo realizado no Centro Sul do Paraná, buscando avaliar o rendimento agronômico e qualidade dos bulbos de 20 cultivares de alho, das quais 12 seminobres e oito nobres, observouse que a cultivar Roxo Caxiense apresentou $54 \%$ de bulbos classificados na categoria 7 (RESENDE et al. 2013), alcançando assim um maior valor agregado no produto.

Em relação à massa de bulbos (Tabela 2), o uso da cama de aviário, apresentou massa de 44,32 g, sendo significativamente superior ao uso de cinza e ao tratamento controle, com 36,6 e 30,3 $\mathrm{g}$, respectivamente, que não diferiram da adubação mineral (42 g) (Tabela 2). A adubação mineral com NPK proporcionou incremento de $28 \%$ no peso de bulbos em relação ao controle. Já a fertilização com cama de aviário permitiu ganhos no peso médio dos bulbos da ordem de 32 e $17 \%$ em relação ao tratamento controle e cinza, respectivamente.

A hipótese inicial desse trabalho era comprovar a viabilidade técnica e econômica do uso de cinza e da adubação com cama de aviário, em relação à adubação mineral, fato esse constatado apenas pelo uso de cama de aviário (Tabelas 2 e 3). Presume-se, que independente dos níveis de $\mathrm{N}$ passíveis de serem disponibilizados por meio da decomposição da matéria orgânica do solo (MOS), a adubação com cinzas seja complementada com o fornecimento de $\mathrm{N}$, pois como exemplificado na Tabela 1, esse material apresenta baixa concentração de N. Corroborando dessa forma com SEGATTO et al. (2012), que avaliando diferentes resíduos, concluíram que os materiais orgânicos necessitam de adubação complementar com nitrogênio mineral para serem utilizados como fonte de nutrientes para as plantas.

Em trabalho realizado com alho vernalizado, MACÊDO et al. (2009) relataram que o aumento na dose de nitrogênio em cobertura chegando até $180 \mathrm{~kg}$ $\mathrm{ha}^{-1}$, possibilitou ganhos lineares em produtividade, além de aumento na porcentagem de bulbos classe 6. Em concordância RESENDE \& SOUZA (2001) avaliando doses de 40,60, 80, 100 e $120 \mathrm{~kg} \mathrm{ha}^{-1}$ $\mathrm{N}$, em diferentes épocas de aplicação, concluíram que a maior produtividade foi obtida na maior dose aplicada. FERNANDES et al. (2011) reportaram que em seu estudo as doses de $\mathrm{N}$ aplicadas em cobertura proporcionaram aumento em produtividade, peso médio dos bulbos e nos valores de índice relativo de clorofila.

Em relação à produtividade de bulbos houve influência dos tratamentos, com eficácia do uso de cama de aviário, que obteve $13405 \mathrm{~kg} \mathrm{ha}^{-1}$ não diferindo da adubação mineral, porém, sendo significativamente superior a cinza e do tratamento controle, com 11071 e $9106 \mathrm{~kg} \mathrm{ha}^{-1}$, respectivamente (Tabela 3). A fertilização com adubação mineral ocasionou uma produção de $12705 \mathrm{~kg} \mathrm{ha}^{-1}$ de bulbos, 
Tabela 2. Diâmetro médio dos bulbos em cm (DMB) e Massa do Bulbo em g (MB). Curitibanos, SC. 2013. Table 2. Average diameter of the bulb in cm (DMB) and bulb mass in $g(M B)$. Curitibanos, SC. 2013.

\begin{tabular}{lll}
\hline & DMB $(\mathrm{cm})$ & MB $(\mathrm{g})$ \\
\hline Testemunha & $41,5 \mathrm{~b}$ & $30,3 \mathrm{c}$ \\
Cama de aviário & $46,5 \mathrm{a}$ & $44,3 \mathrm{a}$ \\
Adubo mineral (NPK) & $45,3 \mathrm{a}$ & $42,0 \mathrm{ab}$ \\
Cinza & $43,8 \mathrm{ab}$ & $36,6 \mathrm{bc}$ \\
\hline
\end{tabular}

Médias seguidas pela mesma letra na coluna não diferem entre si pelo teste de Tukey a 5\%.

Tabela 3. Produtividade e aspectos econômicos do alho em função de fontes de adubação. Curitibanos, SC. 2013.

Table 3. Garlic productivity and economic aspects under sources of fertilization. Curitibanos, SC. 2013.

\begin{tabular}{|c|c|c|c|c|}
\hline & Produtividade $\left(\mathrm{kg} \mathrm{ha}^{-1}\right)^{1}$ & $\begin{array}{c}\text { Incremento } \\
(\%)^{2}\end{array}$ & $\begin{array}{l}\text { Custo por } \\
\text { Tonelada } \\
\left(\mathrm{R} \$ \mathrm{Mg}^{-1}\right)^{3}\end{array}$ & $\begin{array}{l}\text { Lucro por hectare } \\
\qquad\left(\mathrm{R} \$ \mathrm{ha}^{-1}\right)^{4}\end{array}$ \\
\hline Testemunha & $9160,7 \mathrm{c}$ & $-27,9$ & 0,0 & 36642,8 \\
\hline Cama de aviário & $13405,8 \mathrm{a}$ & 5,6 & 167,8 & 51373,2 \\
\hline Adubo mineral (NPK) & $12705,0 \mathrm{ab}$ & - & 127,9 & 49195,0 \\
\hline Cinza & $11464,8 \mathrm{bc}$ & $-9,8$ & 8,7 & 45759,2 \\
\hline
\end{tabular}

${ }^{1}$ Médias seguidas pela mesma letra na coluna não diferem entre si pelo teste de Tukey a $5 \%$.

${ }^{2}$ Incremento (\%) em produtividade em relação ao tratamento convencional (Adubação mineral - NPK).

${ }^{3}$ Custos com adubação para producão de $1,0 \mathrm{Mg}$ de bulbos.

${ }^{4}$ Levando em consideração o preço $\mathrm{R} \$ 4,00$ por Kg de alho e subtraindo apenas o investimento em adubação.

resultado esse que não diferiu das demais formas de adubação testadas, somente do tratamento controle (Tabela 3).

A cama de aviário possui em sua composição compostos nitrogenados (ZÁRATE et al. 1997), entre outros que são fundamentais para o desenvolvimento das culturas. O pico de absorção da cultura do alho ocorre entre os 75 e 90 dias após o plantio para a maioria dos nutrientes, exceto $\mathrm{P}, \mathrm{Ca}$ e Zn (ANDRIOLI et al. 2008). Pelo fato da cama de aviário não conter os nutrientes na forma solúvel, sendo necessária a mineralização para posterior disponibilização dos mesmos, sugere-se que na ocasião de maior demanda pela cultura, havia maior disponibilidade de nutrientes, passíveis de serem absorvidos.

Em concordância, OLIVEIRA et al. (2003) observaram efeito positivo do uso de cama de aviário em repolho. Em trabalho realizado em sistema orgânico, observou-se aumento na produtividade e qualidade do alho de forma linear à medida que se aumentou a dose de $\mathrm{N}$, utilizando como fonte nitrogenada o esterco bovino no plantio e a torta de mamona em cobertura, reportando o benefício de fontes orgânicas (FEITOSA et al. 2010).

A cama de aviário é também fonte de enxofre (BRATTI 2013), fato esse que pode ter beneficiado o alho nesse tratamento. Pois, de acordo com trabalho realizado por SOUZA et al. (2011), o enxofre (S) é o quarto nutriente mais extraído pela cultura do alho. Apesar da similaridade nos teores de Ca e Mg na cinza e na cama de aviário (Tabela 1), e a superioridade no teor de K na cinza (Tabela 1), que segundo SOUZA et al. (2011) é o segundo nutriente mais demandado pela cultura, os baixos teores de $\mathrm{N}$ e $\mathrm{S}$, na cinza foram determinantes para a menor produtividade de alho nesse tratamento (Tabela 3).

Levando em consideração o custo de produção a partir de cada fonte utilizada, observa-se que esses foram menores ao utilizar a adubação com cinzas, pois esta apresenta apenas o custo do frete para o produtor. A quantidade utilizada de adubo mineral correspondeu a um investimento de $\mathrm{R} \$ 1.625,00$ $\mathrm{ha}^{-1}$, resultando num custo de $\mathrm{R} \$ 127,9$ de adubo para cada tonelada de alho produzido (Tabela 3). Enquanto a cama de aviário resultou num investimento de $\mathrm{R} \$ 2.250,00 \mathrm{ha}^{-1}$, refletindo em gasto de $\mathrm{R} \$ 167,8$ de fertilizante para cada tonelada de alho produzido (Tabela 3). Apesar do maior custo por tonelada de alho, na cama de aviário, esse tratamento resultou em maior produtividade, consequentemente num lucro de $\mathrm{R} \$ 2.178,2$ por hectare a mais que o tratamento com adubação convencional. Já ao comparar o lucro 
por hectare proveniente da cinza, este foi $\mathrm{R} \$ 3.435,8$ inferior ao tratamento convencional (Tabela 3 ).

A produtividade obtida no presente estudo pelas fontes de fertilizantes foi superior a produtividade obtida no mesmo ano no município de Curitibanos e a média registrada no estado de Santa Catarina, que obtiveram produtividades de 10000 e $9355 \mathrm{~kg} \mathrm{ha}^{-1}$, respectivamente (IBGE 2014). Fato que enaltece a discussão quanto à viabilidade do emprego de formas alternativas de fertilizantes, tais como as avaliadas nesse estudo. Conhecer a concentração dos nutrientes no fertilizante empregado é uma ferramenta essencial para realização de uma adubação equilibrada e eficiente para a cultura, pois tanto a cinza quanto a cama de aviário apresentam variações em sua composição, principalmente em função do manejo empregado e origem do material carbonizado.

O uso da cinza oriunda da queima de biomassa vegetal não é apto em substituir a adubação mineral, porém, notavelmente por se tratar de um resíduo, é um insumo que apresenta custo reduzido. Sugerese a necessidade de mais estudos nas mais diversas condições edafoclimáticas avaliando a redução da adubação mineral, a partir do uso de cinzas, buscando incremento em produtividade e sustentabilidade do ponto de vista agrícola ambiental.

\section{CONCLUSÃO}

Nas condições de clima e solo do presente estudo a adubação orgânica com cama de aviário mostrou-se ser viável, gerando incremento de 5,6 e $14,5 \%$ em produtividade de bulbos em relação ao uso de adubo mineral e cinza de caldeira, respectivamente.

O uso de cama de aviário apresentou lucro por hectare de $\mathrm{R} \$ 2.178,2$ a mais que a adubação mineral.

\section{REFERÊNCIAS}

ANDRIOLI FF et al. 2008. Curva de crescimento e marcha de absorção de nutrientes pela cultura do alho sob condições de campo. Scientia Agraria 9: 385-393.

BAYER C \& MIELNICZUK J. 1999. Dinâmica e função da matéria orgânica. In: SANTOS GA \& CAMARGO FAO. (Eds.). Fundamentos da matéria orgânica do solo: ecossistemas tropicais e subtropicais. Porto Alegre: Genesis. p.9-26.

BIASI J. 1991. Importância do alho Chonan na expansão da alhocultura nos Estados do Sul. Horticultura Brasileira 9: 69-70.

BIASI J. 2006. Nutrição e indicação de adubação para a cultura do alho. Florianópolis: EPAGRI. 60p. (Boletim
Técnico 132).

BONFIM-SILVA EM et al. 2011. Características produtivas e eficiência no uso de água em Rúcula adubada com cinza vegetal. Enciclopédia Biosfera 7: 178-186.

BRATTI FC. 2013. Uso de cama de aviário como fertilizante orgânico na produção de aveia preta e milho. Dissertação (Mestrado em Zootecnia). Dois Vizinhos: UTFPR. 70p. CQFS-RS/SC - Comissão de Química e Fertilidade do Solo. 2004. Manual de adubação e calagem para os estados do Rio Grande do Sul e Santa Catarina. 10.ed. Porto Alegre: Sociedade Brasileira de Ciência do Solo. 400p.

DAROLT MR et al. 1993. Cinza vegetal como fonte de nutrientes e corretivo de solo na cultura da alface. Horticultura Brasileira 11: 38-40.

EMBRAPA-Empresa Brasileira de Pesquisa Agropecuária. 2013. Centro Nacional de Pesquisas de Solos. Sistema Brasileiro de Classificação de Solos. 3.ed. Rio de Janeiro: Embrapa Solos. 353p.

EPAGRI/CEPA. 2014. Síntese Anual da Agricultura de Santa Catarina: 2013-2014. Florianópolis. Disponível em:

$<$ http://docweb.epagri.sc.gov.br/website_cepa/ publicacoes/Sintese_2014.pdf $>$. Acesso em: 20 set. 2015.

FEITOSA HO et al. 2010. Produtividade e qualidade do alho em função de doses de nitrogênio em sistema orgânico. Agropecuária Técnica 31: 8-13.

FERNANDES LJC et al. 2011. Contribuição das concentrações de nitrogênio em bulbilhos de alho tratados com doses de $\mathrm{N}$ em cobertura. Horticultura Brasileira 29: 26-31.

IBGE - Instituto Brasileiro de Geografia e Estatística 2014. Produção Agrícola Municipal. Disponível em: $\quad$ http://www.sidra.ibge.gov.br/bda/tabela/protabl. asp $? \mathrm{c}=99 \& \mathrm{z}=\mathrm{p} \& \mathrm{o}=29 \& \mathrm{i}=\mathrm{P}$. Acesso em: 19 set. 2015 .

LOURENÇO KS et al. 2013. Crescimento e absorção de nutrientes pelo feijoeiro adubado com cama de aves e fertilizantes minerais. Revista Brasileira de Ciência do Solo 37: 462-471.

MACÊDO FS et al. 2009. Produtividade de alho vernalizado em função de doses de nitrogênio e molibdênio. Bragantia 68: 657-663.

MAPA - Ministério da Agricultura, Pecuária e Abastecimento. 1992. Portaria n. ${ }^{\circ} 242$ de 17 de setembro de 1992. Norma de identidade, qualidade, acondicionamento, embalagem e apresentação do alho. Disponível em: <http:// www.codapar.pr.gov.br/arquivos/File/pdf/alho242_92. pdf>. Acesso em: 22 set. 2015.

MORAL R et al. 2005. Characterization of the organic matter pool in manures. Bioresource Technology 96: 153158.

OLIVEIRA FB et al. 2003. Uso do pré-cultivo de Crotalaria juncea e de doses crescentes de "cama" de aviário na produção do repolho sob manejo orgânico. Agronomia 37: 60-66.

PANDOLFO $\mathrm{C}$ et al. 2002. Atlas climatológico digital do Estado de Santa Catarina. Florianópolis: Epagri (CD-Rom). 
RESENDE JTV et al. 2013. Caracterização morfológica, produtividade e rendimento comercial de cultivares de alho. Horticultura Brasileira 31: 157-162.

RESENDE GM \& SOUZA RJ. 2001. Doses e épocas de aplicação de nitrogênio sobre a produtividade e características comerciais do alho. Horticultura Brasileira 19: 126-129.

SANTOS AD et al. 2009. Manual de análises químicas de solos, plantas e fertilizantes. 2.ed. Brasília: Embrapa Informação Tecnológica. 627p.

SEGATTO MP et al. 2012. Decomposição de resíduos industriais no solo. Ciência e Natura 34: 49-62.

SILVA FR et al. 2013. Uso da cinza da combustão da biomassa florestal como corretivo de acidez e fertilidade de um Cambissolo Húmico. Revista de Ciências Agroveterinárias 12: 304-313.

SOUZA RABMC et al. 2013. Efeito da cinza de caldeira sobre as características químicas de um solo do Cerrado baiano e produtividade da alface. Cultivando o Saber 6: 6073.

SOUZA RJ et al. 2011. Absorção de nutrientes em alho vernalizado proveniente de cultura de meristemas cultivado sob doses de nitrogênio. Horticultura Brasileira 29: 498503.

TEDESCO MJ et al. 1995. Análises de solo, plantas e outros materiais. 2.ed. Porto Alegre: UFRGS. 174p. (Boletim Técnico, 5).

WU L \& MA QC. 2002. Relationship between compost stability and extractable organic carbon. Journal of Environmental Quality 31: 1323-1328.

ZÁRATE NAH et al. 1997. Produção de alface em função de doses e formas de aplicação de cama de aviário semidecomposta. Horticultura Brasileira 15: 65-67.

ZHANG H et al. 2002. Poultry Litter Quality Criteria. Oklahoma cooperative extension service (Production technology, Department of Plant and Soil Sciences. v.14, $\left.n^{\circ} 24\right)$ 